\title{
Breastfeeding among mothers in the public health sector: the role of the occupational therapist
}

\author{
Marieta Visser, B OT (UFS), MSc (OT) (Wits) \\ Lecturer, Department of Occupational Therapy, School for Allied Health Professions, Faculty of Health Sciences, University of the \\ Free State
}

Mariette Nel, MMedSc (Biostatistics) (UFS)

Lecturer, Department of Biostatistics, Faculty of Health Sciences, University of the Free State

\author{
Tanya la Cock, B OT (UFS) ** \\ Netske Labuschagne, B OT (UFS) ** \\ Wihanli Lindeque, B OT (UFS) ** \\ Annelize Malan, B OT (UFS) ** \\ Carli Viljoen, B OT (UFS)
}

** Students in the Department of Occupational Therapy at the University of the Free State at the time the study was carried out

Background and aim: South Africa has an unacceptably high child mortality rate. Preventable causes such as malnutrition account for a high percentage of these deaths. Breastfeeding as infant feeding practice is recognised for its potential to radically reduce child mortality and is therefore promoted globally. Yet, SA presents with the lowest breastfeeding rates worldwide. Breastfeeding is a child rearing co-occupation, and occupational therapists (OTs) are well positioned to become role players on a transdisciplinary level to address the infant child mortality rate through promoting and supporting breastfeeding. Although not well described in the literature and traditionally not considered part of occupational therapy practice, this study aimed to determine the role of the OT in addressing breastfeeding among mothers in the public health sector (PHS).

Method: A purposive sample of 9 OTs from Bloemfontein working in the Public Health Service (PHS) participated in this study. An e-Delphi technique was used to set up four rounds of sequential questionnaires developed from and structured according to the Occupational Therapy Practice Framework (OTPF) Domain and Process.

Results: From the 128 initial statements, 95 statements reached consensus determined at $80 \%$ agreement. Statements were clustered according to OT roles identified, which included clinician, consultant, educator, trainer, advocate and facilitator.

Conclusion: OTs have a role to play in addressing breastfeeding among mothers in the PHS, within a transdisciplinary team. If OTs aligned their practice with global and national initiatives and policies, the population-based health issue of infant child mortality could be addressed collectively.

Keywords: child mortality; breastfeeding; child rearing; co-occupation; Delphi technique

\section{INTRODUCTION}

Globally, malnutrition is the leading cause of child mortality'. Based on current projections, between 2015 and 2028, 35 million children will die world-wide before their fifth birthday ${ }^{2}$, unless the call to improve child survival is strengthened within population-based health. These deaths in children are largely due to preventable causes, such as pneumonia, diarrhoea and malaria, which mostly occur in children weakened by malnutrition ${ }^{3-5}$. Therefore, malnutrition should be prevented, considering that it is the right of every child to have access to basic nutrition ${ }^{6,7}$.

The infant feeding practice of breastfeeding is recognised as the greatest strategy in combating malnutrition and alleviating child mortality ${ }^{8-10}$. Inappropriate infant feeding practices are a significant threat to child health ${ }^{\prime \prime}$. The many health benefits that breastfeeding holds regarding an infant's nutritional needs and immune system, have been well researched ${ }^{8,12,13}$. Exclusive breastfeeding has also been proven to pose minimal risk for mother-to-child transmission of the human immunodeficiency virus (HIV) ${ }^{14}$. The benefits overarch the lifespan of the mother-child-dyad, contributing to a stronger bond and mental and physical wellbeing ${ }^{15}$. Investment in early childhood development during critical periods has been shown to positively contribute to socio-economic aspects relating to human capital $^{10,15-17}$. Yet, the exclusive breastfeeding rate (mothers only breastfeeding with no additional feeding) of only $8 \%$ in South Africa is the lowest in the world ${ }^{18}$, directly relating to the unacceptably high rate of 47000 deaths annually among children younger than five years of age ${ }^{2,18,19}$.

When dealt with in a transdisciplinary team ${ }^{20}$, breastfeeding has the potential to address this population-based crisis of infant mortality. Although the Occupational Therapy (OTy) profession is grounded on the construct of "supporting and promoting health through participation in occupations"21:S1,22:507, including the child rearing co-occupation of breastfeeding, Occupational Therapists (OTs) have not traditionally considered it within the scope of their profession to address breastfeeding in the public health sector (PHS). Consequently, the role of the Occupational Therapist (OT) in this regard, as a member of the transdisciplinary team, is not well described in the literature.

Globally and nationally, ample guiding initiatives aim to promote breastfeeding with the aim of alleviating child mortality. The 2005 
Innocenti Declaration of Infant and Young Child Feeding recognises the significance of breastfeeding to improve infant survival and support child health" ${ }^{\prime}$. Furthermore, the release of the 2010 World Health Organization (WHO) guidelines on HIV and infant feeding ${ }^{14}$ transformed existing breastfeeding agendas into a key child survival strategy. The fourth Millennium Developmental Goal (count-down 2015) aimed to reduce child mortality by two thirds, which South Africa has failed to fully achieve $e^{5,3,22}$. Building on the progress made globally, the two new sets of targets include the Sustainable Developmental Goals ${ }^{23}$, and A Promise Renewed: Committing to Child Survival2,9. The Tshwane Declaration resolutions direct South Africa to promote, support and protect breastfeeding ${ }^{24}$. The Infant and Young Child Feeding Policy (IYCFP)' ${ }^{\prime}$ is an initiative that demonstrates South Africa's commitment towards promoting child health, and provides clear guidelines regarding feeding the infant in the context of HIV.

Considering these guiding initiatives, the call for a response from OTs as members of the health profession echoes with the ethos of 'A Promise Renewed', which stated that child survival is a shared responsibility and everyone has a contribution to make ${ }^{2}$. Since OTs are well positioned within the transdisciplinary team, to become role players in the child rearing co-occupation of breastfeeding, they should become involved with initiatives aimed at protecting, promoting, and supporting breastfeeding ${ }^{10,11,20}$.

This article reports on a study that aimed to investigate the role of the OT in addressing breastfeeding among mothers in the PHS, and further provides a review of the literature and recommendations.

\section{LITERATURE REVIEW}

According to the Occupational Therapy Practice Framework (OTPF) Domain and Process, 3rd edition ${ }^{21}$, breastfeeding is considered as one of the "instrumental activities of daily living" (IADLs), which are defined as "activities to support daily life within the home and community that often require more complex interactions than those used in ADLs"21:S19. Within the broad range of IADLs, breastfeeding will be more specifically classified as a "...child rearing activity" $21: 519$ defined as "providing care and supervision to support the developmental needs of a child" ${ }^{21: 519}$. Furthermore, occupation that "implicitly involves two or more individuals may be termed co-occupations" $21: 542$. It involves active participation on the part of both the caregiver and the recipient of care. It is also referred to as a mother-child dyad ${ }^{20}$.

The child rearing co-occupation of breastfeeding transcends the typical classifications of eating and feeding ${ }^{10,21}$, and this relationship benefits both the mother and child across the lifespan ${ }^{15}$, resulting in a positive impact on the greater society. Breastfeeding is indeed "the great equaliser"25:1,26:6 as infants from all social or economic backgrounds, who are optimally fed, have an equal start on a healthy life.

Breastfeeding is also the most nutritious and economical method of feeding an infant ${ }^{12}$, making it an ideal solution in poverty stricken countries, such as South Africa where $45.5 \%$ of the population live in poverty ${ }^{27}$. One of the benefits of breast milk is that it contains antibodies that boost the infant's immune system, providing protection against numerous infections $\mathbf{s}^{8,12,13,28}$.

Breastfeeding has long-term benefits for the mother, which include a decreased risk of ovarian and breast cancer, and facilitating weight loss to a pre-pregnancy level, thereby reducing the risk for type 2 diabetes and metabolic syndrome ${ }^{10,12,13}$. Breastfeeding also reduces the risk of depression and promotes a general sense of physical health in the mother ${ }^{15}$.

For the society and economy, breastfeeding benefits include decreased annual public healthcare costs, decreased absenteeism of the working mother with associated loss of family income, and a decreased environmental burden for production, transport and disposal of artificial feeding products ${ }^{10,16}$. With regard to the management of population growth, breastfeeding has a contraceptive effect which contributes to family planning ${ }^{10}$ and natural spacing of children ${ }^{25}$.

In order to explain how OTy fits into the bigger picture in addressing breastfeeding, we will use Labbok's ${ }^{20}$ framework of four pillars for population-based breastfeeding support. These pillars are (i) national and governmental commitments aimed at supporting the rights of women and children; (ii) legislations and policies regarding infant feeding; (iii) improving health worker skills and health system support; and (iv) improving family and community practices.

The first two pillars are concerned with world leaders' vision of a brighter future. As we enter a post-millennial era, actions are intensified through initiatives such as the Sustainable Developmental Goals $^{23}$, and A Promise Renewed: Committing to Child Survival ${ }^{2}$, with the target to attain 20 or fewer deaths under the age of five per 1000 live births by $2035^{9,29}$. South Africa has aligned itself with the first two pillars by forming policies such as the Tshwane Declaration $^{24}$ and the Infant and Young Child Feeding Policy (IYCFP) ${ }^{\prime}$ that recognise the urgency of improving breastfeeding rates. The IYCFP specifically states that all healthcare personnel require sufficient knowledge and training in child feeding in order to provide support for mothers ${ }^{2}$. It also guides OTs to apply their unique set of knowledge and skills to live up to the core credence of promoting health and wellbeing through participation and engagement in occupations ${ }^{30}$.

The third pillar constitutes public health-related issues. The PHS of South Africa serves $82 \%$ of the population ${ }^{31}$. For every 100000 individuals there are 430 healthcare workers ${ }^{32}$ and 2.6 $\mathrm{OTs}^{31,33}$. Consequently, collaboration between all disciplines is vital for a transdisciplinary approach to population-based health. A population-based health approach enables OTs to deliver cost- and time-effective services to a larger population group when compared to one-on-one intervention, while simultaneously applying the fourth pillar of providing and facilitating support to families and communities. OTs are therefore well positioned to become role players in promoting and supporting breastfeeding.

The role of OTs is defined as the attributes and behaviours expected of them when they act in accordance with their responsibility as they are held accountable by the standards of OT practice ${ }^{34}$. Research is required to articulate the value of the profession's involvement in addressing child survival in South Africa. Therefore, clarifying the OT's role within the transdisciplinary team regarding breastfeeding is critical to address the unacceptably high child mortality rate in South Africa.

The aim of the study was to determine the role of the OT in addressing breastfeeding among mothers in the public health sector (PHS).

\section{METHODS}

An observational, descriptive study design using the Delphi technique. The Delphi technique, a research approach used to structure group communication about practice-related problems, and is known for consensus development by using multiple rounds of data collection, was used ${ }^{35,36}$. It seeks consensus on a certain topic among a panel of experts when there is limited evidence on a topic. For this study, the electronic Delphi (e-Delphi) ${ }^{35}$ was used to clarify a specific role in OTy relating to breastfeeding and to determine the extent of agreement and disagreement over given OTy roles relating to breastfeeding. The Delphi process in this study extended to four rounds in an iterative manner, i.e. questions in the second round were developed based on the responses from the first round. Consensus was determined at $80 \%$ agreement ${ }^{35,37}$.

\section{Ethics}

Approval for this study was obtained from the Ethics Committee of the Faculty of Health Sciences at the University of the Free State. To ensure ethical conduct, written permission was received from the Head of the Free State Province Department of Health $(\mathrm{DOH})$ and written consent was obtained from all participating OTs prior to the study. 


\section{Study participants}

The population consisted of a homogeneous group of 36 OTs $(\mathrm{N}=36)$ practising within the PHS in Bloemfontein (personal communication; Corné Vrey, I5 February 2015). The PHS consists of one primary care hospital, one secondary care hospital, one tertiary care hospital and approximately 43 clinics.

The inclusion criteria for the study were as follows: qualified OTs, female, with experience in paediatrics, who have practised in the PHS of Bloemfontein within the previous five years. The OTs should have had experience in the field of paediatrics in areas such as developmental screening clinics, where the therapist had access to mothers and children two years of age or younger. For practical reasons, the therapists needed to be literate in English, competent in the use of a computer and have internet access.

The 36 OTs working in PHS were all informed about the study and invited to participate. Through purposeful selection ${ }^{35,37}$, thirteen OTs who met the inclusion criteria were approached telephonically and invited to participate. Each of these OTs was read a study overview from the same pre-planned script. This overview informed the possible participants that a maximum of four rounds were possible within the Delphi process and that the participants who completed the study would be remunerated for their time with six continuous professional development (CPD) points, (Clearance to allocate these CPD points was obtained prior to the study). The OTs who considered participation in this study, were then e-mailed a comprehensive information sheet and a consent form. Nine therapists $(n=9)$ consented to participate and formed the panel of experts after which they received a code to ensure confidentiality. These experts (panel members) included therapists from the following clinical areas; Pelonomi Regional Hospital (5 therapists), Universitas Academic Hospital (3 therapists), MUCPP Clinic (I therapist).

\section{Measurement instrument}

The questionnaire for Round I was developed from the Occupational Therapy Practice Framework (OTPF) Domain and Process, 3 rd edition ${ }^{21}$. Each OTPF domain area (i.e. occupational areas; client factors; performance skills; performance patterns and contextual and environmental factors), as indicated in Table $I$, was considered in the development of the questions and hence reflected accordingly in the questionnaire of Round I. A baseline question was formed and adapted for each aspect of the domain, for example: "What role can the OT assume in addressing breastfeeding in the following Occupational Areas: Sleep" (the latter is altered according to the specified aspect of the domain). The questionnaire of Round I consisted of six sections, of which section one comprised 10 demographic questions, and the other five sections represented the five OTy domain areas, consisting of a total of 24 open-ended questions.

Two objective reviewers (an OT with experience in the field of paediatrics and breastfeeding and an expert in the use of the Delphi technique) revised the draft of the questionnaire for Round I and

Table I: Aspects of the Domain of Occupational Therapy from the OTPF 3rd edition ${ }^{21}$ :S4Beferi, Ti. Artermihil vitatui dessena tericiendeo ita que firma, us nosus

\begin{tabular}{|c|c|c|c|c|}
\hline Occupations & $\begin{array}{l}\text { Client } \\
\text { factors }\end{array}$ & $\begin{array}{l}\text { Performance } \\
\text { skills }\end{array}$ & $\begin{array}{l}\text { Performance } \\
\text { patterns }\end{array}$ & $\begin{array}{l}\text { Contexts and } \\
\text { environments }\end{array}$ \\
\hline $\begin{array}{l}\text { Activities of daily } \\
\text { living (ADLs)* } \\
\text { Instrumental } \\
\text { ADLs (IADLs) } \\
\text { Rest and sleep } \\
\text { Education } \\
\text { Work } \\
\text { Play } \\
\text { Leisure } \\
\text { Social } \\
\text { participation }\end{array}$ & $\begin{array}{l}\text { Values, } \\
\text { beliefs and } \\
\text { spirituality } \\
\text { Body } \\
\text { functions } \\
\text { Body } \\
\text { structures }\end{array}$ & $\begin{array}{l}\text { Motor skills } \\
\text { Process skills } \\
\text { Social } \\
\text { interaction } \\
\text { skills }\end{array}$ & $\begin{array}{l}\text { Habits } \\
\text { Routines } \\
\text { Rituals } \\
\text { Roles }\end{array}$ & $\begin{array}{l}\text { Cultural } \\
\text { Personal } \\
\text { Physical } \\
\text { Social } \\
\text { Temporal } \\
\text { Virtual }\end{array}$ \\
\hline
\end{tabular}

*Also referred to as basic activities of daily living (BADLs) or personal activities of daily living (PADLs). modifications were made accordingly before it was sent out. The modifications included adding definitions of terminology to ensure that the knowledge of the OTs was not assessed, but rather that their professional opinion was obtained; improved user-friendliness of the questionnaire; and incorporating the OTPF domain together with the process, in an information letter.

For Round I, the panel members received an information letter and the Round I questionnaire via e-mail, with three working days to complete this questionnaire. A description of Round 2 to Round 4 will follow in the Result section.

\section{Data collection and analysis}

SurveyMonkey ${ }^{\mathrm{TM}, 38}$ was used to electronically compile and distribute the four rounds of questionnaires. The primary investigator (study leader) and student researchers compiled the content of the questionnaires for each round, consolidated the statements and re-entered the questionnaires for each round onto SuveyMon$\mathrm{key}^{\mathrm{TM}}$. Descriptive statistics, namely frequencies and percentages for categorical data, and medians and percentiles for continuous data, were calculated by the Department of Biostatistics of the University of the Free State.

\section{RESULTS}

In Round I, it was determined that the panel members had a median of 8 years paediatric experience, with all levels of public healthcare represented. Four had personal experience with breastfeeding (meaning that they had personally breastfed their own child), ranging from 3 to more than 12 months. The opinion relating to breastfeeding of the panel members were influenced by personal and clinical experience, relatives and friends. Table II indicates the aspects that influenced their opinion gauged on a 4-point Likert scale.

Table II: Aspects that influenced the participants' current opinion regarding the role of the OT in addressing breastfeeding

\begin{tabular}{|c|c|c|}
\hline Aspects & $\begin{array}{c}\text { Likert scale } \\
\text { median }\end{array}$ & \multirow{5}{*}{$\begin{array}{l}\text { Key } \\
\text { I= No influence } \\
2=\text { Minimal influence } \\
3=\text { Moderate influence } \\
4=\text { Major influence }\end{array}$} \\
\hline Personal experience & 3.5 & \\
\hline Relatives & 3 & \\
\hline Friends & 3 & \\
\hline Clinical experience & 3.5 & \\
\hline
\end{tabular}

The questionnaire distributed in Round I (representing the five OTy domain areas and consisting of 24 open-ended questions) provided the researchers with 216 responses. The responses were consolidated to generate a list of 128 statements.

In Round 2, the panel members had to either agree or disagree with the I 28 statements. At the end of each section a question was also asked to establish if the OT considered that specific role as either unique to the profession, or an aspect that could be addressed in the transdisciplinary team. They were given two working days to complete this questionnaire. Consensus was reached on 91 statements.

For Round 3, the 37 statements on which consensus was not reached, re-entered the Delphi process. The panel members had two working days to complete this questionnaire. Consensus was reached on three more statements, resulting in a total of 94 statements on which panel members reached consensus.

For Round 4, the remaining 34 statements re-entered the Delphi process. The panel members had one working day to complete this questionnaire. Consensus was reached on one more statement, giving a total of 95 statements on which consensus was eventually reached. Due to time constraints, the remaining 33 statements were not re-entered into a next round. 
Table III: Examples of key statements on which the panel reached consensus, according to the domains of occupational therapy, indicating the role of the OT in addressing breastfeeding

\section{Occupational areas}

Activities of daily living (ADLs) and instrumental ADLs

\section{Work}

Educate and improve insight of mothers regarding the importance and benefits of breastfeeding, including those for her own body, so as to encourage her to breastfeed.

Educate the mother on Kangaroo Mother Care.

Assist with learning new skills and organising times for expressing breast milk at work in order to continue breastfeeding for as long as possible.

Refer to a dietician when necessary.

Education

Create parent training sessions to empower the mothers and emphasise the importance of breastfeeding: providing information and knowledge on the benefits of breast milk including financial benefits.

If the mother is still of school-going age, encourage her to continue breastfeeding / expressing milk.

Act as advocate for the rights of our clients.

Play

Provide insight on adequate stimulation or play for the infant's age, e.g. visual tracking - mother's face, focus, head control.

Leisure

Consult and provide knowledge on the importance of constructive and balanced leisure activities, i.e. to relieve stress and improve health in order to increase milk production.

Social participation

Assist contact-making with a support group in the community to share their experiences, skills and advice regarding breastfeeding.

Rest and sleep

Relaxation therapy or relaxation techniques can be taught.

Educate and encourage mothers and family members on the effect of sleep on milk production and prevention of burnout.

Provide information on infant sleep cycles, how to provide correct stimulation to promote continuation of sleep cycles, adequate awake time for each age between daily naps/sleeps as well as night sleeps. Implementing an optimal daily routine, as well as sensory diet to promote optimal sleep patterns.

Environmental adaptations to promote sleep, i.e. arranging the room for the baby and self.

\section{Contextual and environmental factors}

Cultural environment $\quad$ Provide basic knowledge, principles, and insight with regard to breastfeeding as far as possible within the context of the family's cultural environment.

Plan or be part of organising activities (e.g. international breastfeeding week) to make people of all cultures and communities more aware of the advantages of breastfeeding.

Personal environment

Establish support groups which can offer knowledge that may better equip mothers to make better decisions.

Physical environment

Assess the mother's physical environment to adapt training to suit what she has available at home.

Encourage and assist the mother in creating a suitable, non-disturbing, hygienic and quiet environment for breastfeeding.

Social environment

Involve family (especially the father) and friends and motivate the mother to identify and utilise possible support systems in her environment that can support her with breastfeeding.

Temporal context

Virtual context Promoting interaction and eye contact of infant with mothers during breastfeeding.

Depending on the socio-economic status of the mother and thus technological devices available, the OT can inform the patient of media platforms where more information is available.

\section{Performance patterns}

Habits

Address habits that negatively affect breastfeeding and baby development or habits that could interfere with normal performance in occupations (smoking and drinking while breastfeeding). Teach the importance of healthy habits and the impact thereof on the child.

Routines

Educate and assist the mother on how to establish a routine in order to manage breastfeeding and other tasks inbetween, e.g. organising other small children while breastfeeding.

Educate the mother and give her insight in how often and when it is necessary to breastfeed the baby (learn to read the baby's cues).

Rituals Working client-centred by knowing and respecting the rituals that are part of the mother's life.

Roles

Providing the mother with insight and educating her on the roles and responsibilities of a breastfeeding mother.

\section{Performance skills}

Motor skills

Teach correct handling and positioning of the baby (i.e. with the hips and neck supported and body kept in correct alignment, hand in midline or on mother's breast for self-regulation and bonding through touch).

Assist with physical rehabilitation, or adaptation of actual task of breastfeeding, including handling and positioning of the baby and providing assistive devices, when the mother has neurological impairments, or any additional pathologies. 
.....Table III continuted from page 68

\begin{tabular}{|l|l|}
\hline Process skills & $\begin{array}{l}\text { If a mother has suffered a stroke during delivery then adaptations will need to be made in terms of handling and } \\
\text { positioning during breastfeeding as there may be cognitive impairments. }\end{array}$ \\
\cline { 2 - 2 } & $\begin{array}{l}\text { Teach the mother to read the infants stress cues and sleep states; to stimulate the baby to become more alert for } \\
\text { optimal feeding. }\end{array}$ \\
\hline Social interaction skills & $\begin{array}{l}\text { Facilitate eye contact during breastfeeding and encouraging the mother to be calm and relaxed. Teach the mothers } \\
\text { that the infant must be in quiet alert state, encourage mothers to talk and interact with their infants before and after } \\
\text { feeding. }\end{array}$ \\
\hline Client factors & $\begin{array}{l}\text { Respect, acknowledge and encourage mothers to explore and define their values, beliefs and spirituality regarding } \\
\text { breastfeeding. }\end{array}$ \\
\hline $\begin{array}{l}\text { Values, beliefs, } \\
\text { spirituality }\end{array}$ & $\begin{array}{l}\text { Motivate the mother to breastfeed as this promotes quicker returning of the pre-pregnancy body, through this the } \\
\text { healthy mother will feel better about herself. }\end{array}$ \\
\hline Body functions and \\
body structures & $\begin{array}{l}\text { Support the mother during possible breastfeeding difficulties or when faced with other medical issues, disabilities or } \\
\text { prematurity. Refer to medical practitioners as needed. }\end{array}$ \\
\hline
\end{tabular}

Table III includes some examples of the 95 statements on which the panel reached consensus. These statements were considered to be key statements in reflecting the essence of the results from the Delphi rounds. The complete list of statements is available on request from the corresponding author. The statements are presented according to the aspects of the OTy domain as they appear in the OTPF $3^{\text {rd }}$ edition ${ }^{21}$ and do not imply a specific hierarchy.

The study concluded with the panel reaching $74.2 \%$ (95/I28) consensus on the given statements, indicating agreement among participating OTs in the PHS regarding their potential role in promoting and supporting breastfeeding. Given the choice to agree or disagree with the given statements, the panel agreed with 94 statements, and disagreed with one statement. The one statement regarding the role of the OT, the panel disagreed on was "Promoting/raising awareness in the community of the different cultural beliefs on breastfeeding and accommodating it".

The roles that the OT can assume, as deducted from the 95 statements shown in Table III, were clustered according to roles identified in literature ${ }^{21,34}$. These roles are as follows and the number of statements which indicated this particular role is provided in brackets ie clinician (27), consultant (17), educator (16), trainer (9), advocate (9) and facilitator (I7), which will be described accordingly in the discussion ${ }^{21,34}$. (See Table IV)

\section{DISCUSSION}

With the holistic client-centred approach to the mother-child dyad in the co-occupation of breastfeeding being identified as embedded within several statements, this study revealed that OTs could provide a unique and valuable service ${ }^{2 !}$.

The definite agreement among OTs in the PHS regarding the various roles they can potentially assume to promote and support breastfeeding, is congruent with existing literature and global and national initiatives.

The role as a clinician, who has direct contact with the mother ${ }^{39}$, was evident in statements that OTs could make environmental adaptations and assistive devices for breastfeeding mothers. The results are supported by literature stating that OTs could assess and adapt the infant and mother's sleeping environment ${ }^{10}$. The OT can also strengthen the infant-parent bond by encouraging eye contact and a calm and relaxed mood in the mother ${ }^{15}$.

The role of consultant, to provide expert advice ${ }^{40}$, includes the establishment of insight into the importance of leisure activities and adequate rest and sleep in order to address the well-being of the breastfeeding mother. By advising mothers to exclusively breastfeed, OTs will ensure that mothers reap the benefits from the physiological impact that breastfeeding has on sleep, compared to mixed- or formula-feeding ${ }^{15}$. Consultation could also include

Table IV: Examples of statements indicating the different roles that the OT can assume in addressing breatfeeding

\begin{tabular}{|l|l|}
\hline Role of the OT & Brief description/examples of statements \\
\hline $\begin{array}{l}\text { Clinician } \\
\text { One who works directly with patients }{ }^{39}\end{array}$ & $\begin{array}{c}\text { Promote infant-mother bonding through breastfeeding, stimulating eye-contact and infant massage } \\
(5 / 27) .\end{array}$
\end{tabular}

One who works directly with patients ${ }^{39} \quad(5 / 27)$.

- Assist mothers with meaningful engagement in occupations, including leisure- and work related activities (4/27).

- Adapt sleeping environment of mother and infant to promote a healthy sleeping- and day/night breastfeeding routine $(4 / 27)$.

- Provide client-centred therapy that incorporates the patient's cultural context that provides alternative and adaptive methods of breastfeeding (5/27).

- Make adaptations to the breastfeeding environments that are conducive to breastfeeding, eg. non-disturbing, hygienic and quiet using the resources available $(3 / 27)$.

- Rehabilitate mother or infant in alternative methods of breastfeeding if a physical disability is present by using alternative methods and assistive devices (6/27).

Consultant

One who gives expert advice or service ${ }^{40}$
- Identify problematic areas related to breastfeeding that can be best addressed by other service providers, for example, expressing difficulties to the dietician, or poor social circumstances to the social worker (5/I7).

- Promoting the mother's wellbeing through emphasising healthy leisure choices and empowering her to experience her role and responsibilities as a mother positively, which can be addressed in collaboration with other service providers (4/17).

- Inform the mother how she can stimulate the infant's developmental milestones and play, especially if the mother is a school going mother, first-time mother or mother of a disabled child (3/I7).

- Inform mother of media platforms that can provide additional information to the mother ( $1 / 17)$.

- Provide information on the sensory processing profile, sensory- and self-regulatory behaviour and sleeping cycle of the infant $(2 / 17)$. 
......Table IV continuted from page 69

\begin{tabular}{|c|c|}
\hline $\begin{array}{l}\text { Educator } \\
\text { One who imparts information to the } \\
\text { mother }{ }^{4 I}\end{array}$ & $\begin{array}{l}\text { - Educating mothers on how to establish routines, targeting the working- and school going mothers, } \\
\text { in order to enhance breastfeeding period }(5 / 16) \text {. } \\
\text { - Fostering a sense of responsibility as a breastfeeding mother, and generating insight among the } \\
\text { mothers on the effect of their choices regarding social habits, such as drinking, will have on the } \\
\text { child }(4 / 16) \text {. } \\
\text { - Addressing a community through providing insight among mothers on healthy breastfeeding } \\
\text { practices that will encourage a change in cultural perceptions and practices in communities }(3 / 16) \text {. } \\
\text { - Educating mothers on the benefits of breastfeeding }(2 / 16) \text { and the importance of social support } \\
\text { structures }(2 / 16) \text {. }\end{array}$ \\
\hline $\begin{array}{l}\text { Trainer } \\
\text { One who teaches a specific skill }{ }^{21,42}\end{array}$ & $\begin{array}{l}\text { - Train the mother in Kangaroo Mother Care }(3 / 9) \text {. } \\
\text { - Teach relaxation therapy and relaxation techniques }(1 / 9) \text {. } \\
\text { - Train mother how to read the infant's feeding queues and how to stimulate the infant into a quiet } \\
\text { alert state before feeding }(3 / 9) \text {. } \\
\text { - Teach different breastfeeding positions }(1 / 9) \text {. } \\
\text { - Empower the mother in understanding her own child and how to seek assistance in addressing a } \\
\text { problem }(1 / 9) \text {. }\end{array}$ \\
\hline $\begin{array}{l}\text { Advocate } \\
\text { To plead for the cause of another }{ }^{43}\end{array}$ & $\begin{array}{l}\text { - Provide a platform, either through educational groups or awareness campaigns where mothers can } \\
\text { voice their concerns and explore their own understanding of breastfeeding and where they can be } \\
\text { provided with information and solutions }(6 / 8) \text {. } \\
\text { - Fight for the rights of the mother and infant }(1 / 8) \text {. } \\
\text { - Encourage support systems for the breastfeeding mother at home and at the workplace }(1 / 8) \text {. }\end{array}$ \\
\hline $\begin{array}{l}\text { Facilitator } \\
\text { One who uses a group as medium to } \\
\text { support the mother }{ }^{21}\end{array}$ & $\begin{array}{l}\text { - Facilitate contact with a support group close to the mother's home as well as with organisations } \\
\text { that can provide healthy leisure options and support to the new mother }(3 / 17) \text {. } \\
\text { - Provide opportunity for mothers to partake in healthy leisure time activities }(1 / 17) \text {. } \\
\text { - Provide training sessions that improve the insight into all the benefits of breastfeeding, equipping } \\
\text { a mother to make informed decisions and form healthy habits that support her breastfeeding (in } \\
\text { contrast to smoking and drinking) }(3 / 17) \text {. } \\
\text { - Establish a support group where mothers can connect with other mothers in her community } \\
\text { where mutual learning and support can take place within an appropriate cultural environment } \\
\text { - U/I7). } \\
\text { support the mother in breastfeeding }(2 / 17) \text {. }\end{array}$ \\
\hline
\end{tabular}

referral to and collaborative work with the appropriate health team members (e.g. dietician). The results also indicated that OTs could provide information on sensory profiles, typical developmental and age-appropriate play stimulation.

Literature emphasises the use of media platforms (such as mHealth) by health professionals to make information more accessible to the larger population. However, no reference has been made to existing media platforms such as mHealth Alliance ${ }^{44}$, MAMA SA initiative ${ }^{45}$ or MomConnect ${ }^{46}$, that could be used by OTs as consulting tools. The use of mobile health technology is therefore an underexplored intervention media in comparison to the more traditional "hands-on" intervention strategies in the OTy profession, and should receive urgent investigation.

The OT also has an educational role, which entails imparting information to the mother ${ }^{4 l}$ regarding the value of breastfeeding that correlates with the objectives of the Infant and Young Child Feeding ${ }^{1: 16}$. Similarly, suggestions to assist the mother in creating a routine and establishing healthy habits are supported by Pitonyak ${ }^{10}$, who explains that the OT has expert knowledge in establishing performance patterns conducive to breastfeeding. Further, it has been indicated that educating a mother on the roles and responsibilities that accompany her newly acquired occupation of breastfeeding, will ease the occupational identity change ${ }^{21,47}$.

As a trainer, the study supported the role that OTs could play in teaching the mother specific skills ${ }^{42}$ regarding Kangaroo Mother Care and reading infant stress cues ${ }^{1,10}$. The results indicated that OTs could teach skills regarding correct positioning of the baby and relaxation techniques that will contribute to the mother's well-being.

The facilitator role on a primary healthcare level includes, amongst others, OTs assisting in the establishment of support groups. Such group intervention strategies, where collective involvement of the family and close friends is obtained ${ }^{10}$, can influence the motivating and positive choice-making among mothers ${ }^{1,21}$. Providing an opportunity for mothers to learn within a group environ- ment, allows transference of knowledge pertaining to breastfeeding, and allows OTs "to standardise and harmonise messages relating to infant and young child nutrition"::12.

The role of advocate, to plead for the cause of another ${ }^{43}$, is perhaps, in the South African context and in light of our high infant mortality rate, a pertinent role that OTs should more actively assume. However, no consensus was achieved on similar statements, which can indicate unawareness amongst OTs of the guiding policies relating to breastfeeding. The role of an advocate is strongly supported by the Tshwane Declaration, which encourages healthcare personnel, including OTs, to promote breastfeeding. Advocating for extended maternity leave, creating supportive environments in the workplace and school (for teenaged mothers) $)^{1,48}$ and being involved in awareness campaigns such as World Breastfeeding Week, are possible areas of intervention ${ }^{1,48}$. Furthermore, acting as an advocate is a population-based approach through which societal perceptions can be broken down and social norms supportive of breastfeeding can be cultured ${ }^{10}$.

In accordance with the literature ${ }^{1,10,20}$ and the four pillar framework for population-based breastfeeding support ${ }^{20}$, the growth potential of the profession has been emphasised through the roles identified in this study.

The implication of these roles requires that the profession of occupational therapy makes a shift regarding the traditional perspective of not having a definite role in addressing breastfeeding. Through acting in accordance with the objectives outlined by the overarching legislation and policies in South Africa, namely the IYCFP and Tshwane Declaration, the role of the OT in this regard can be established.

The execution of this study was limited by a time schedule which consequently restricted the study to four rounds. Although a small sample of 9 OTs participated, they represented a reasonable sample of the population of 36 OTs currently working in the PHS. One of the strengths of the study was the absence of participant dropout. 


\section{RECOMMENDATIONS}

The unacceptably high child mortality rate in South Africa can best be addressed through a population based approach. Breastfeeding, recognised for the potential to radically reduce child mortality, should be promoted and supported by all role players on a transdisciplinary level in the PHS. Although supporting and promoting breastfeeding traditionally belonged to the nursing profession, breastfeeding is a child rearing co-occupation, and occupational therapists (OTs) are therefore also well positioned to become role players.

Since the promotion and support of breastfeeding are underexplored in the OTy profession, many areas where OTs can potentially be involved have emerged and hence the following recommendations are proposed.

With regard to clinical practice, OTs can ensure that the services that they render are aligned with the relevant national and international guiding initiatives and policies. OTs can act upon their responsibility towards mothers and children through implementing above mentioned initiatives and policies, as well as the suggested actions described underneath each role that an OT can assume, as fitting the specific clinical setting.

The use of alternative delivery of services through media platforms, including mobile health technologies such as MomConnect $^{31,45,46}$, is strongly recommended for OTs. Through becoming involved in the content of media messages that include the OT professions contribution will allow them to broaden their clientele to include individuals, groups, communities and populations, ensuring a population-based health approach within the PHS.

We recommend that an increased awareness of international and national guiding documents ${ }^{49}$ relating to infant health and feeding practices (including breastfeeding) be incorporated into OTy undergraduate training, to foster a broader population-based transdisciplinary health approach with students. A 24-hour breastfeeding course has already been implemented at the University of the Free State.

A strong transdisciplinary approach, without overlapping other pertinent health professionals' roles in breastfeeding (such as nursing), is recommended. An occupational perspective on breastfeeding will contribute to a holistic approach. OTs can, for example, collaborate more with community health workers, especially in areas where services are insufficient and assess the services already available to establish best intervention strategies to complement the other professions. This can be done through regular screening, follow-up appointments with complicated cases, support groups, and awareness and promotion campaigns in the community to name a few examples.

Lastly, we recommend further research on the current statements on which consensus was reached in the Delphi survey, on a larger panel of experts on a national level, to further clarify the identified roles of OTs in breastfeeding promotion. Research is also needed to investigate the impact of OTs addressing breastfeeding, establishing evidence-based practice. So as to standardise the role of the OT in breastfeeding as determined by evidence-based practice that may be implemented throughout the PHS.

\section{CONCLUSION}

There is conclusive agreement among participating OTs regarding the potential role within the transdisciplinary team, in promoting and supporting breastfeeding among mothers in the PHS. The Delphi technique enabled participants to identify the specific roles that OTs can potentially assume. Roles that emerged from the study included that of clinician, consultant, educator, trainer, facilitator and advocate. However, further delineation of the OTs' role in addressing the co-occupation of breastfeeding is indicated on larger samples.

In obligation to international and national guiding initiatives, OTs in the public health services in South Africa are called into action to assume their role within the transdisciplinary team (without overlapping with other health professionals' roles), for the improvement of a population-based health crisis - child mortality rates related to malnutrition. With this matter in mind, it has to be emphasised that breastfeeding remains a life and death issue that can only be addressed collectively.

\section{ACKNOWLEDGEMENTS}

Dr. Christel Troskie-de Bruin, ASEV Research and Development Consultants; and Dr. Daleen Struwig, Faculty of Health Sciences, UFS, are acknowledged for editorial and technical preparation of the manuscript.

\section{REFERENCES}

I. National Department of Health (NDoH), Republic of South Africa. South African Infant and Young Child Feeding Policy. Pretoria: Department of Health South Africa; 20I3. [Accessed 4 November 20I5]. Available from: www.kznhealth.gov.za/.../Infant_and_young_child_ feeding policy.pdf.

2. UNICEF. Committing to child survival: a promise renewed. Progress Report 2013. [Accessed 6 June 2015] Available from: http://www. unicef.org/lac?Committing_to_Child_Survival_APR_9_Sept_2013. pdf.

3. UNICEF. 2013 Statistical snapshot: Child Mortality. [Accessed I6 June 20I5]. Available from: www.childinfo.org/files/Child_Mortality_Stat_Snapshot_e-version_Sep_17.pdf.

4. World Health Organization $(\overline{\mathrm{W}} \mathrm{HO})$. Essential nutrition actions improving maternal, newborn, infant and young child health and nutrition. 2013. [Accessed 22 September 2013]. Available from: http://apps. who.int/iris/bitstream/10665/84409/1/978909/1/978924 I505550_ eng.pdf.

5. Republic of South Africa. Millennium Development Goals: country report 2013. [Accessed 3I July 20I5]. Available from: http://www. za.undp.org/content/dam/south_africa/docs/Reports/The_Report/ MDG_October-2013.pdf.

6. United Nations (UN). Convention on the Rights of the Child. GA Res.44/25 United Nations, Treaty Series vol. I577, no. 2753 I. 1989. [Accessed II March 2008]. Available from: http://www.unhchr.ch/ $\mathrm{html} / \mathrm{menu} 3 / \mathrm{b} / \mathrm{k} 2 \mathrm{crc} . \mathrm{htm}$.

7. Republic of South Africa. The Constitution of the Republic of South Africa. 1996. [Accessed I6 June 2015]. Available from: http://www. justice.gov.za/legislation/constitution/SAConstitution-web-eng.pdf.

8. Doherty T, Sanders D, Goga A, Jackson D. Implications of the new WHO guidelines on HIV and infant feeding for child survival in South Africa. Bulletin of the World Health Organization, 20I I; 89(I): 62-67.

9. Liu L, Oza S, Hogan D, Perin J, Rudan I, Lawn JE, Cousens S, Mathers C, Black RE. Global, regional, and national causes of child mortality in 2000-13, with projections to inform post-2015 priorities: and updated systematic analysis. Lancet, 20I5; 385 (9966): 430-440.

10. Pitonyak JS. Occupational therapy and breastfeeding promotion: our role in societal health. American Journal of Occupational Therapy, 2014; 68(3): e90-96.

II. UNICEF. Celebrating the Innocenti Declaration on the Protection, Promotion and Support of Breastfeeding. 2005. [Accessed 16 June 2015]. Available from: http://www.unicef-irc.org/publications/ pdf/190-2005-gb.pdf.

12. World Health Organization (WHO). Global Health Observatory. [Accessed 26 March 20I4]. Available from: http://www.who.int/ gho/child_health/mortality/neonatal_infant_text/en/.

13. Young SL, Mbuya MNN, Chantry $\bar{C}$, Geubbels EP, Israel-Ballard $K$, Cohan D, Vosti SA, Latham MC. Current knowledge and future research on infant feeding in the context of HIV: basic, clinical, behavioural, and programmatic perspectives. Advances in Nutrition, 20I I; 2(3): 225-243.

14. World Health Organization (WHO). Guideline on HIV and infant feeding 2010. [Accessed 28 July 2015]. Available from: http://whqlibdoc. who.int/publications/2010/9789241599535_eng.pdfua = I.

15. Kendall-Tackett K. It's not just milk - it's relationship. Recent findings in neuroscience show breastfeeding's effects throughout the lifespan. Clinical Lactation, 2014; 5(2): 37-40.

16. Ketan G, Ketan S. Breastfeeding and the use of human milk. Pediatrics, 2005; II5(2): 496-506.

17. Kibel M, Saloojee H, Westwod T. Child health for all: A Manual for South Africa. 5th Edition, Oxford University Press, Cape Town, 2012 
18. UNICEF UNICEF and WHO welcome South Africa's efforts to protect and support breastfeeding. 20I2. [Accessed I6 June 20I5]. Available from: http://www.unicef.org/southafrica/media_10469. html.

19. Child Mortality Estimates. CME Info. Home Page. 2014. [Accessed 31 July 20I5]. Available from: www.childmortality.org.

20. Labbok $\mathrm{MH}$. Transdisciplinary breastfeeding support: creating program and policy synergy across the reproductive continuum. International Breastfeeding Journal, 2008; 3:16.

21. American Occupational Therapy Association (AOTA). Occupational therapy practice framework: domain and process. $3^{\text {rd }}$ edition. American Journal of Occupational Therapy, 20I4; 68: SI-S48.

22. Muir S. Occupational therapy in primary health care: we should be there. American Journal of Occupational Therapy, 2012; 66(5): 506-510.

23. Sustainable Development Knowledge Platform. Open Working Group proposal for Sustainable Development Goals. 2015. [Accessed 29 July 20I5]. Available from: http://sustainabledevelopment.un.org/ sdgsproposal.html.

24. National Department of Health (NDoH), Republic of South Africa. The Tshwane declaration of support for breastfeeding in South Africa. South African Journal of Clinical Nutrition, 20I I; 24(4): 2 I4.

25. Labbok MH. Breastfeeding: population-based perspectives. Pediatric Clinics of North America, 20 I 3; 60(I): I I-30.

26. United Nations System Standing Committee on Nutrition. Nutrition for improved development outcomes. $5^{\text {th }}$ Report on the World Nutrition Situation. 2004. [Accessed 31 July 20 15]. Available from: http://www.unsystem.org/scn/Publications/AnnualMeeting/SCN3I/ SCN5Report.pdf.

27. Statistics South Africa. Poverty trends in South Africa: an examination of absolute poverty between 2006 and 20I I. 20I4. [Accessed 2 May 20 I4]. Available from: http://beta2.statssa.gov.za/publications/ Report-03-10-06/Report-0310-06March2014.pdf.

28. Zulliger R, Adams EJ, Myer L. Diversity of influences on infant feeding strategies in women living with HIV in Cape Town, South Africa: a mixed methods study. Tropical Medicine and International Health, 20I3; 18(I2): I547-I554.

29. UNICEF. Child Mortality Report 2014. [Accessed 3 June 20I5]. Available from: http://www.data.unicef.org/fckimages/uploads/I 40869227 child_Mortality_Report_2014.pdf.

30. World Federation of Occupational Therapists (WFOT). Statement on Occupational Therapy. 2011. [Accessed 9 June 2015]. Available from http://www.wfot.org/Portals/0/PDF/STATEMENT\%200N\%20 OCCUPATIONAL\%20THERAPY\%203008II.pdf.

31. Mars M. Telerehabilitation in South Africa - is there a way forward? International Journal of Telerehabilitation, 201 I; 3(I): II-18.

32. Global Health Workforce Alliance and World Health Organisation. A universal truth: no health without a workforce. 2014:I-90.

33. Health Systems Trust. South African Health Review 20/3//4. 2014. [Accessed 16 June 2015]. Available from: http://www.hst.org.za/ publications/south-african-health-review-2013/14.

34. Creek J. Occupational therapy defined as a complex intervention. United Kingdom: College of Occupational Therapists (COT); 2003.

35. Keeney S, Hasson F, McKenna H. The Delphi Technique in Nursing and Health Research. Chichester: Wiley-Blackwell; $201 \mathrm{I}$.

36. Vernon W. The Delphi technique: a review. International Journal of Therapy and Rehabilitation, 2009; 16(2):69-76.

37. Wilkes L, Cioffi J, Cummings J, Warne B, Harrison K. Clients with chronic conditions: community nurse role in a multidisciplinary team. Journal of Clinical Nursing, 2013; 23(5-6): 844-855.

38. SurveyMonkey. Create surveys, get answers. 2015. [Accessed 23 August 2015]. Available from: http://www.surveymonkey.com/.

39. Merriam-Webster. Definition of clinician. 2016. [Accessed 17 June 2016]. Available from: http:www.merriam-webster.com/dictionary/clinician.

40. Merriam-Webster. Definition of consultant. 2016. [Accessed I7 June 2016]. Available from: http://www.merriamwebster.com/dictionary/ consultant.

41. Dictionary.com. Definition of education. 2016. [Accessed 17 June 2016]. Available from: http://www.dictionary.com/browse/education.

42. Oxford Dictionary. Definition of trainer. 2015. [Accessed 26 September 20I5]. Available from: http://www.oxforddictionaries.com/ definition/english/training

43. Dictionary.com. Definition of advocate. 2015. [Accessed 26 September 2015]. Available from: http://dictionary.reference.com/ browse/advocate.

44. United Nations Foundation. Expanding mHealth knowledge with mHealth alliance resources. mHealth knowledge by K4Health. 2015 . [Accessed 27 September 2015]. Available from: http://mhealthknowledge.org/content/expanding-mhealth-knowledge-mhealthalliance-resources.

45. MAMA South Africa. Reimaging mobile in South Africa: lessons from year one. 2014. [Accessed 20 August 2014]. Avialble from: http://mobilemamaalliance.org/sites/default/files/Reimagining\%20 Mobile\%20Mobile\%20in\%20South\%20Africa.\%20Lessons\%20 from\%20Year\%200ne.pdf.

46. VP Health System. MomConnect: improving healthcare to mothers and babies. Challenges and lessons in setting up and using mobile technology to address gaps in the continuum of care towards meeting the goals of EMTCT. 2013. [Accessed 20 August 20I4]. Available from: http:// www.vphealth.co.za/resources/MomConnect_Poster.pdf.

47. Buskens I, Jaffe A. Demotivating infant feeding counselling encounters in southern Africa: do counsellors need more or different training? AIDS Care, 2008; 20(3): 337-345.

48. World Health Organization (WHO). Comprehensive implementation plan on maternal, infant and young child nutrition. 2014. [Accessed 2 March 2015]. Available from: http://apps.who.int/iris/bitstream/I0665/I I 3048/I/WHO_NMH_NHD_I4.I_eng.pdf?ua + I .

49. International Food Policy Research Institute. Global Nutrition Report 2015: Actions and Accountability to Advance Nutrition and Sustainable Development. 2015. Washington, DC.

Corresponding Author

Marieta M Visser

vissermm@ufs.ac.za 